\title{
The Natural History of Osteoarthritis: What Happens to the Other Hip?
}

\author{
Harlan C. Amstutz MD, Michel J. Le Duff MA
}

Received: 1 December 2015/Accepted: 4 May 2016/Published online: 12 May 2016

(C) The Association of Bone and Joint Surgeons (B) 2016

\begin{abstract}
Background Idiopathic osteoarthritis (OA) is a common diagnosis leading to hip arthroplasty. Patients undergoing unilateral hip arthroplasty often wonder whether their other hip will follow the same path as the one that was operated on, and if so, when? There also are limited data available to predict from AP radiographs which contralateral hips will have OA develop and which will not.

Questions/purposes We sought (1) to determine the incidence of contralateral osteoarthritic degeneration in a group of patients who were treated with unilateral hip arthroplasty; and (2) to identify clinical and radiographic features associated with the development of contralateral OA.

Methods Between 1998 and 2010, we performed 398 hip arthroplasties on patients with unilateral primary hip OA,
\end{abstract}

Each author certifies that he, or a member of his immediate family, has no funding or commercial associations (eg, consultancies, stock ownership, equity interest, patent/licensing arrangements, etc) that might pose a conflict of interest in connection with the submitted article.

All ICMJE Conflict of Interest Forms for authors and Clinical Orthopaedics and Related Research $\mathbb{R}$ editors and board members are on file with the publication and can be viewed on request.

Clinical Orthopaedics and Related Research $\mathbb{B}$ neither advocates nor endorses the use of any treatment, drug, or device. Readers are encouraged to always seek additional information, including FDAapproval status, of any drug or device prior to clinical use.

Each author certifies that his institution approved or waived approval for the human protocol for this investigation and that all

investigations were conducted in conformity with ethical principles of research.

H. C. Amstutz ( $\square)$, M. J. Le Duff

Joint Replacement Institute, 2200 West Third Street, Suite 400,

Los Angeles, CA 90057, USA

e-mail: harlanamstutz@verity.org who at the time of surgery did not have any symptoms in the contralateral hip. Of those, 367 (92\%) had a minimum 2-year radiographic followup (mean, 11 years; range, 2-17 years). The 31 patients dropped from the study for lack of radiographic followup had comparable preoperative features as the study group. We performed a radiographic analysis on the baseline AP radiographs to see what factors were associated with arthritis progression, and we performed Kaplan-Meier survivorship analysis with contralateral hip pain and contralateral THA as the endpoints.

Results Kaplan-Meier survival estimates indicated that 10 years after the baseline evaluation, 59\% (95\% CI, 53\%$65 \%$ ) of the patients remained free of symptoms on the contralateral hip and $81 \%$ (95\% CI, 75\%-85\%) remained free of an arthroplasty on the contralateral hip. Sex, age, weight, or BMI were not associated with the development of OA on the contralateral hip with the numbers available. Reduced minimum joint space width (hazard ratio, 0.299; 95\% CI, 0.237-0.378), low center-edge angle (hazard ratio, 0.941; 95\% CI, 0.915-0.968), low head-to-neck ratio (hazard ratio, 1.555; 95\% CI, 1.088-2.223), and the presence of osteophytes (hazard ratio, 1.453; 95\% CI, 1.0012.110) were associated with the development of contralateral OA. In hips with a center-edge angle greater than $25^{\circ}$, a head-to-neck ratio of 1.3 or less increased the chances of development of OA by $86 \%$ (hazard ratio, 1.857; 95\% CI, 1.235-2.793).

Conclusions The variables we studied can easily be assessed from an AP pelvis radiograph so physicians can predict the occurrence of contralateral OA and the need for future hip arthroplasty in their patients needing unilateral arthroplasty. However, the data available might have led us to underestimate the need for contralateral arthroplasty. Future studies with a prospective design should aim at 
completing the list of radiographic features associated with the development of OA by adding a review of lateral radiographs.

Level of Evidence Level IV, prognostic study.

\section{Introduction}

In their daily clinical practice, surgeons performing hip arthroplasties often are asked by their patients whether their other hip will follow the same path as the one that was operated on, and if so, when? Ritter et al. [18] found that $37 \%$ of contralateral hips diagnosed as "normal" would have osteoarthritis (OA) develop within 10 years, and $8 \%$ would undergo THA. Vossinakis et al. [20] found that patients with unilateral idiopathic OA are more likely to have OA develop in the contralateral hip than patients with hip dysplasia. Şahin et al. [19] found that features of femoroacetabular impingement are seen more frequently in the asymptomatic contralateral hip of patients who have undergone hip arthroplasty secondary to idiopathic OA than in control subjects.

Two of these studies were very limited in statistical power $[19,20]$, whereas the third included various etiologies and did not present a risk factor analysis [18]. Therefore, there still is a paucity of information to answer this question. Only a long-term longitudinal study can help determine how often and after what amount of time the second hip is likely to become symptomatic and require surgery. Patient characteristics and hip-specific anatomic features are likely to play a role in the rate of development of OA and ultimately the need for arthroplasty because true cases of idiopathic hip OA are thought to be quite rare [11, $13,15]$.

The purposes of our study were (1) to determine the incidence of contralateral osteoarthritic degeneration in a group of patients who were treated with unilateral hip arthroplasty; and (2) to identify clinical and radiographic features associated with the development of contralateral OA.

\section{Patients and Methods}

Between 1998 and 2010, we performed 398 hip arthroplasties on patients with unilateral primary hip OA, who at the time of surgery were free of pain in the contralateral hip (Charnley Class A disease). The patients were included regardless of the radiographic findings of the contralateral hip at baseline as long as they had no pain. Of those, 367 (92\%) had a minimum 2-year radiographic followup (mean, 11 years; range, 2-17 years). The median followup for the study group was 103 months (range, 24-205 months).
The study group included 295 men and 72 women, predominantly white, with a mean age of 54 years \pm 8 years. Their mean height was $1.77 \pm 0.09 \mathrm{~m}$. Their mean weight was $86 \pm 18 \mathrm{~kg}$ and their mean BMI was $27 \pm 4 \mathrm{~kg} / \mathrm{m}^{2}$. Followups were scheduled annually for the first 5 years and at 2- to 4-year intervals thereafter and included clinical and radiographic evaluations. University of California Los Angeles (UCLA) hip scores [1] were collected and the pain score of the contralateral hip was used to determine the patients' Charnley classification. We chose to define Charnley Class B as the presence of pain in the contralateral hip, although this class initially was defined by pain interfering with walking ability.

The time between the index and the contralateral hip arthroplasty also was recorded for the patients who underwent contralateral surgery. Baseline AP pelvis radiographs were performed at the time of the initial surgery and used to collect data on seven variables of interest, including minimal and maximal joint space width $[5,16]$ in DeLee and Charnley Zone 1 [6], center-edge angle of Wiberg [21], femoral head-to-neck ratio, the presence of femoral head cysts and osteophytes, and the femoral headto-neck feature known as "pistol-grip deformity" [11]. The joint space was qualified as eccentric whenever the difference between maximum and minimum joint space width was greater than $1 \mathrm{~mm}$. We used Einzel-Bild-RoentgenAnalyse (EBRA-Cup version 2003; University of Innsbruck, Innsbruck, Austria) to digitally delineate the contour of the femoral head and determine the location of the hip center of rotation. We then used Image J Version 1.41 image processing and analysis software (National Institutes of Health, Bethesda, MD, USA) to perform the above-cited measurements (Fig. 1). All measurements were normalized using the known diameter of the components used in the contralateral hip arthroplasty. Pistol-grip deformity was defined as a hip for which the superior cortex did not intersect the circle of the femoral head at the head-neck junction (Fig. 2). The 31 patients who were dropped from the study for lack of radiographic followup were comparable to patients in the study group in age $(\mathrm{p}=0.950)$, gender composition ( $p=0.411)$, BMI $(p=0.306)$, minimum joint space $(\mathrm{p}=0.135)$, maximum joint space $(\mathrm{p}=$ $0.793)$, center-edge angle $(p=0.584)$, and head-to-neck ratio $(\mathrm{p}=0.368)$. In addition, 80 patients $(22 \%)$ from the study group had not been followed in the last 5 years, including 14 (4\%) who had not been followed for 10 years and could be considered lost to followup. These patients were included as they had the minimum 2-year followup and showed no difference from the rest of the study group for the above-cited variables $(\mathrm{p}>0.05)$. In addition, 157 patients $(43 \%)$ from the study group who were included because they reported no pain in the contralateral hip 


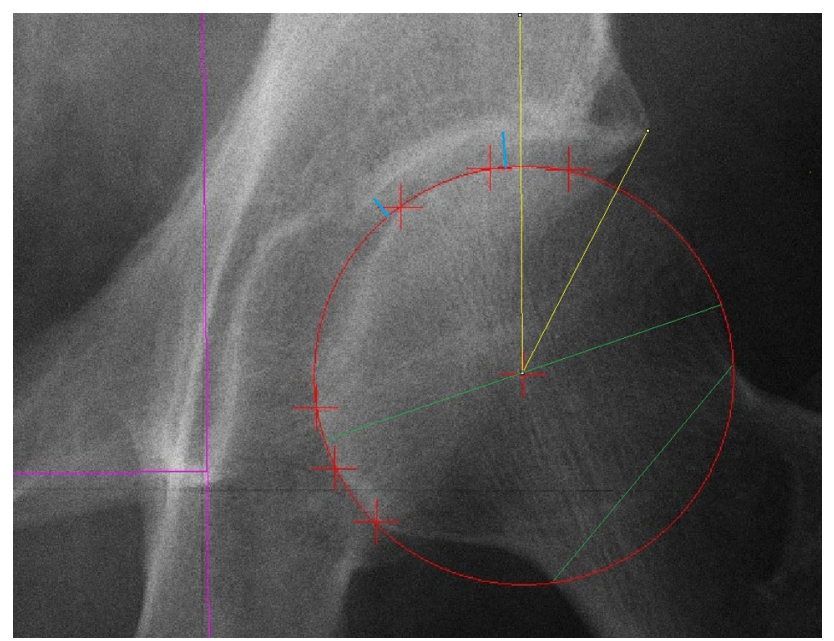

Fig. 1 The measurements performed on the baseline AP radiographs are shown. The circle was constructed by interpolation of the points placed on the femoral head by the experimenter (red "Xs"). These points were positioned on the part of the femoral head that was covered by the acetabulum to ensure using the part of the head actually involved in articulation during normal gait. The region of the fovea, however, was avoided to better match the circular portion of the head. Other measurements included head-to-neck ratio (green lines), joint space width (blue lines), and center-edge angle (yellow lines).

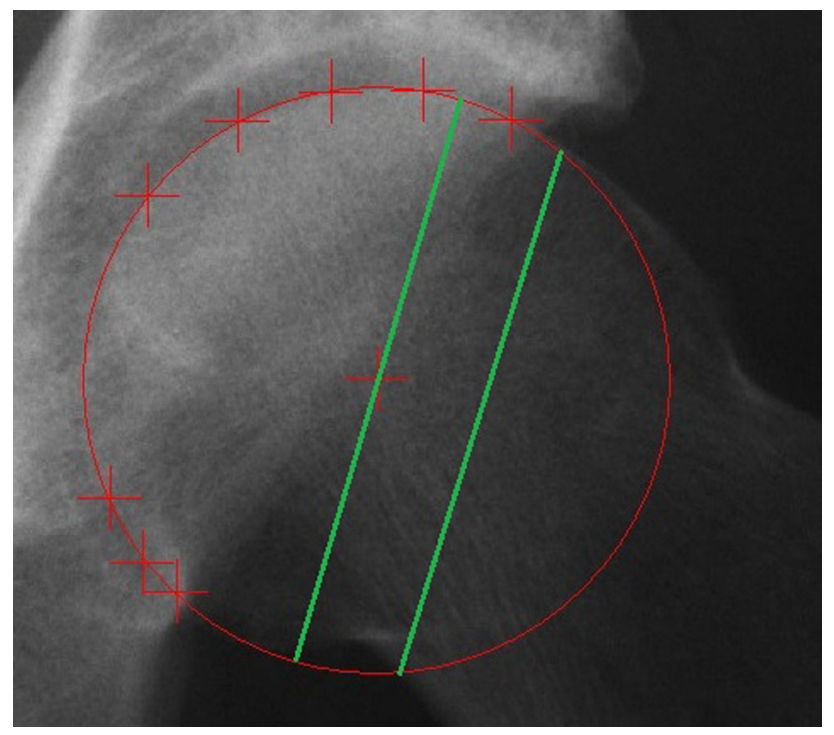

Fig. 2 A femoral head with a pistol-grip deformity is seen in this radiograph. The superior part of the femoral neck lies entirely outside the circle defined by the articular part of the head, suggesting the possibility of impingement where the femoral neck and the circle separate. The neck diameter was measured from this impingement point to the intersection of the inferior cortex with the circle.

already showed radiographic signs of OA on the baseline film: $14(4 \%)$ had a mimimum joint space less than $2 \mathrm{~mm}$, 116 (32\%) had osteophytes, and 27 (7\%) had both.
At the time the surgery was performed, the senior author (HA) informed the patient that when the opposite hip had radiographic features similar to those of the replaced hip, that hip was at risk but that there was no concrete evidence to predict when it would become arthritic. The patients were advised to avoid high levels of activity to prolong the life of the contralateral hip. In addition, if the patient had a loss of internal rotation, it was suggested to avoid using full ROM because of the possible consequences of impingement.

Power calculations showed that a minimum sample size of 32 conferred $80 \%$ power of detecting a $0.5-\mathrm{mm}$ difference in joint space width between patients who had Charnley Class A disease and those who had contralateral symptoms develop. Two Kaplan-Meier survival estimates were computed, the first one using the time from baseline evaluation to the change to Charnley Class B as the endpoint (defined as onset of pain) and the second using the time to contralateral surgery as the endpoint. A multivariate analysis was performed using the Cox proportional hazard ratio to determine the effect of demographic characteristics of patients, activity level, and radiographic measurements on the development of contralateral OA (patient having disease progress to Charnley Class B). Sixty-two patients had a center-edge angle of $25^{\circ}$ or smaller. We performed a similar multivariate analysis on patients with low center-edge angle $\left(25^{\circ}\right.$ or smaller) and patients with a center-edge angle greater than $25^{\circ}$ to further investigate the interaction between this variable and the characteristics of the femoral head-to-neck junction. The alpha level was set at 0.05 . All analyses were conducted using Stata ${ }^{\circledR}$ Intercooled 6.0 (Stata ${ }^{\circledR}$, College Station, TX, USA).

\section{Results}

The majority of patients who underwent unilateral hip arthroplasty remained symptom free in the contralateral hip for at least 10 years and did not undergo contralateral hip replacement. Kaplan-Meier survivorship, free of any symptoms, was $73 \%(95 \% \mathrm{CI}, 68 \%-78 \%)$ at 5 years, $59 \%$ (95\% CI, 53\%-65\%) at 10 years, and 39\% (95\% CI, 30\%$48 \%$ ) at 15 years (Fig. 3). For patients who became symptomatic $(\mathrm{n}=150)$, the median time for symptoms to develop was 44 months (range, 4-198 months). Fifty-nine patients eventually underwent contralateral hip arthroplasty. Kaplan-Meier survivorship, free of hip arthroplasty, was $87 \%(95 \% \mathrm{CI}, 83 \%-90 \%)$ at 5 years, $81 \%(95 \% \mathrm{CI}, 75 \%-85 \%)$ at 10 years, and $75 \%$ (95\% CI, $66 \%-81 \%$ ) at 15 years (Fig. 4). In the 59 patients who eventually underwent contralateral hip arthroplasty ( $\mathrm{n}=$ 59), the median time to surgery was 58 months (range, 10 161 months). 
After controlling for potential confounding variables, such as participation in sports, we found that minimum joint space width, center-edge angle, the presence of osteophytes, and a head-to-neck ratio of 1.3 or less were associated with the development of hip symptoms (Table 1). With the numbers available, we did not find any associations between gender (hazard ratio [HR], 1.005; 95\% CI, 0.669-1.508; $\mathrm{p}=0.981)$, age (HR, 1.001; 95\% CI,

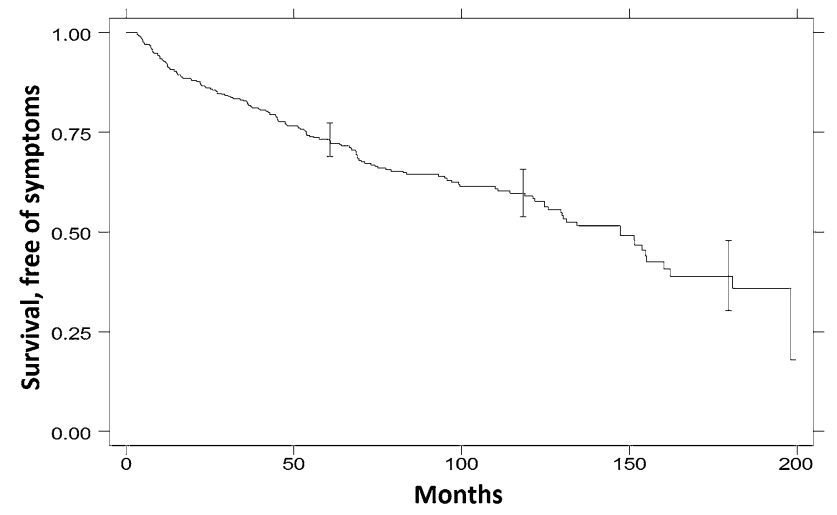

Fig. 3 The Kaplan-Meier survival curve using the time to progression to Charnley Class B disease as the endpoint is shown.

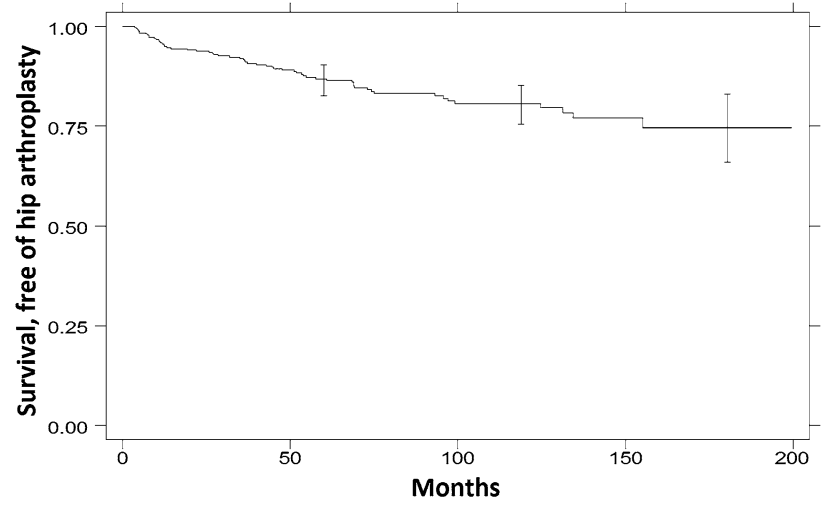

Fig. 4 The Kaplan-Meier survival curve using the time to contralateral surgery as the endpoint is shown.
0.981-1.020; $\mathrm{p}=0.935)$, height (HR, 1.007; 95\% CI, $0.988-1.026 ; \mathrm{p}=0.483)$, weight $(\mathrm{HR}, 1.001 ; 95 \% \mathrm{CI}$, $0.992-1.010 ; \mathrm{p}=0.836$ ), and BMI (HR, 0.997; 95\% CI, $0.961-1.035 ; \mathrm{p}=0.888$ ) and the development of symptoms in the contralateral hip. Head-to-neck ratio was not associated with the appearance of symptoms in the subgroup of patients with a center-edge angle of $25^{\circ}$ or less (Table 2). In contrast, among the patients with a center-edge angle larger than $25^{\circ}$, a head-to-neck ratio of 1.3 or less substantially increased the chances of appearance of symptoms (Table 3).

\section{Discussion}

The fate of the contralateral hip is often a source of concern for patients undergoing unilateral hip arthroplasty. Previous attempts to answer questions regarding incidence and risk factors for the development of OA of the contralateral hip either lacked statistical power [19, 20], or did not investigate the radiographic features that could indicate future development of OA [18]. In this study, we aimed to determine the proportion of patients who would have OA and contralateral hip symptoms develop, and the proportion who would opt for contralateral hip arthroplasty, in a group of patients who were treated with unilateral hip arthroplasty.

Our study has some limitations. First, the radiographic review focused only on AP radiographs, whereas it is well documented that the shape of the anterior femoral head-toneck junction can be the source of cam-type impingement leading to OA [9]. Lateral radiographs of the contralateral hip were not available for our review, which could have enhanced our analysis [8] and possibly provided answers for some unexplained variability. However, preoperative radiographs rarely include lateral films of the contralateral hip when the patient is undergoing unilateral hip arthroplasty and the only image available for the surgeon to make a prognostic evaluation of the contralateral hip is the AP film. In that respect, the information provided in our

Table 1. Multivariate analysis showing the effect of variables on development of OA on contralateral hip*

\begin{tabular}{llll}
\hline Variable & Hazard ratio & p value & 95\% CI \\
\hline Participation in sports & 0.892 & 0.527 & $0.626-1.271$ \\
Minimum joint space width $(\mathrm{mm})$ & 0.299 & 0.001 & $0.237-0.378$ \\
Center-edge angle $\left(^{\circ}\right)$ & 0.941 & 0.001 & $0.915-0.968$ \\
Osteophyte & 1.453 & 0.050 & $1.001-2.110$ \\
Head-to-neck ratio $\leq 1.3$ & 1.555 & 0.015 & $1.088-2.223$ \\
\hline
\end{tabular}

* Time to shift from Charnley Class A to Charnley Class B was used as endpoint; OA = osteoarthritis. 
Table 2. Multivariate analysis showing the effect of variables with $\mathrm{CE}$ of $25^{\circ}$ or less*

\begin{tabular}{lllr}
\hline Variable & Hazard ratio & p value & 95\% CI \\
\hline Participation in sports & 0.630 & 0.251 & $0.287-1.385$ \\
Minimum joint space width $(\mathrm{mm})$ & 0.371 & 0.001 & $0.226-0.609$ \\
Osteophyte & 1.263 & 0.575 & $0.559-2.850$ \\
Head-to-neck ratio $\leq 1.3$ & 0.889 & 0.768 & $0.408-1.937$ \\
\hline
\end{tabular}

Time to shift from Charnley Class A to Charnley Class B was used as endpoint; CE = center edge.

Table 3. Multivariate analysis showing the effect of the variables with CE larger than $25^{\circ *}$

\begin{tabular}{lllr}
\hline Variable & Hazard ratio & p value & $95 \%$ CI \\
\hline Participation in sports & 0.862 & 0.474 & $0.574-1.295$ \\
Minimum joint space width $(\mathrm{mm})$ & 0.272 & 0.001 & $0.206-0.358$ \\
Osteophyte & 1.356 & 0.172 & $0.876-2.098$ \\
Head-to-neck ratio $\leq 1.3$ & 1.857 & 0.003 & $1.235-2.793$ \\
\hline
\end{tabular}

* Time to shift from Charnley Class A to Charnley Class B was used as the endpoint; CE = center edge.

study still should be of great value. Second, although our patients reported no pain in the contralateral hip at the time of evaluation, some showed radiographic features suggesting that the osteoarthritic process was already engaged, such as the presence of osteophytes or reduced joint space. The severity of the osteoarthritic changes could have affected measurement of radiographic parameters [14] in these patients. However, we elected to keep these patients in our cohort because they are part of the population who will inquire about the future of their contralateral hip. Third, the investigators (HA, ML) who reviewed the radiographs also were involved in the clinical followup of the patients and therefore not blinded to the outcome. However, the image processing was made in two steps: the preparation of the images with EBRA and then radiographic measurement and evaluation of the 357 radiographs, which was performed from a separate directory, devoid of clinical indicator of the outcome. Fourth, we chose to define Charnley Class B as the presence of pain in the contralateral hip, although Charnley Class B initially was defined by pain interfering with walking ability. Our definition may be somewhat more sensitive, increasing the number of patients with osteoarthritic progression because some of our patients went from a UCLA pain score of 10 or 9 to an 8 or lower without recording a disturbance in walking ability and still had a UCLA walking score of 10. Fifth, 31 patients from the eligible population did not have 2-year followup data. If these patients had been different from those in the study group in any of the variables studied, this could have invalidated our findings. Fortunately that was not the case. In addition, 80 patients from the study had not been followed in the last 5 years and 14 were considered lost to followup. A case could be made for patients lost to followup having a greater chance of having had revision surgery [17] than the rest of the cohort, leading to underestimation of the occurrence of contralateral hip arthroplasty. However, it is our experience that in a country where medical services often incur substantial expenses for the patient, a large portion of the patients lost to followup actually are doing well and do not see the point of followups. This argument is supported by a study validating the use of survivorship analysis in orthopaedics [7]. Finally, our patient population was predominantly white patients and this reduces the potential for inference of our study results to other ethnic groups who do not have the same prevalence of primary OA. Our first result is the survivorship of the contralateral hip as pain free. Our findings of $41 \%$ progressing to Charnley Class B disease is consistent with the finding of Ritter et al. [18]; they found $37 \%$ of normal hips had OA develop at 10 years. They also found that $8 \%$ of these hips would undergo hip arthroplasty, a percentage lower than our $19 \%$ (Table 4). This could be because a substantial number of hips in our cohort were included because they showed no symptoms at baseline evaluation but already had indicators that the osteoarthritic process was engaged. Similarly, Goker et al. [10] noted a $21 \%$ rate of hip arthroplasty performed during the course of their study. These survivorship results also are consistent with the findings of Vossinakis et al. [20], who reported an increased risk of development of contralateral OA in patients with idiopathic OA in one hip, and the results of Clohisy et al. [3], who found a high prevalence of structural abnormalities consistent with femoroacetabular impingement in patients with 
Table 4. Summary of studies in which development of OA was studied on the contralateral hip after arthroplasty

\begin{tabular}{|c|c|c|c|c|}
\hline Study & Journal & Year & Number & Findings \\
\hline Ritter et al. [18] & J Arthroplasty & 1996 & 1116 patients (664 with normal hips) & $\begin{array}{l}\text { Contralateral OA } 79 \% \text { at } 10 \text { years with } 54 \% \\
\text { with THA; in normal hips } 37 \% \text { OA and } 8 \% \\
\text { with THA }\end{array}$ \\
\hline Goker et al. [10] & Arthritis Rheum & 2000 & 99 patients & $\begin{array}{l}\text { Eighty-five percent of patients maintained a } \\
\text { slow decline in joint space width }(<0.2 \\
\mathrm{mm} / \text { year }) \text {, and } 15 \% \text { had an accelerated } \\
\text { decline in joint space width }(>0.2 \mathrm{~mm} / \\
\text { year); } 21 \% \text { underwent contralateral THA }\end{array}$ \\
\hline Vossinakis et al. [20] & Skeletal Radiol & 2008 & 95 patients (56 with idiopathic OA) & $\begin{array}{l}\text { Idiopathic OA of one hip increases risk of } \\
\text { contralateral OA; prediction difficult only } \\
\text { from radiographic measurements; } \\
\text { weightbearing surface best predictor }\end{array}$ \\
\hline Şahin et al. [19] & $J$ Int Med Res & 2011 & $\begin{array}{l}44 \text { subjects with idiopathic OA } \\
\text { and } 40 \text { control subjects }\end{array}$ & $\begin{array}{l}\text { No difference in center-edge angle but } \\
\text { femoroacetabular impingement features } \\
\text { more prevalent in contralateral hip of } \\
\text { patients with idiopathic OA }\end{array}$ \\
\hline Current study & $\operatorname{CORR}^{\circledR}$ & 2016 & 367 patients & $\begin{array}{l}\text { Forty-one percent of patients progress to } \\
\text { Charnley Class B disease, of which } 19 \% \\
\text { undergo hip arthroplasty within } 10 \text { years; } \\
\text { joint space width, center-edge angle, head- } \\
\text { to-neck ratio, and osteophytes predicted } \\
\text { development of OA; center-edge angle less } \\
\text { than } 25^{\circ} \text { counteracts the effect of a low } \\
\text { head-to-neck ratio }\end{array}$ \\
\hline
\end{tabular}

$\mathrm{OA}=$ osteoarthritis

idiopathic $\mathrm{OA}$ and a high rate of subsequent contralateral THA.

Among the four risk factors for development of OA that we found in this study (low minimum joint space width, low center-edge angle, low head-to-neck ratio, and presence of osteophytes), the strongest predictor of the change to Charnley Class B disease was a low minimal joint space width. We found a $71 \%$ decrease in the risk of change to Charnley Class B for each 1-mm increment (Table 1). This result correlates the findings of some authors who showed associations of joint space width with development of symptoms or the need for hip arthroplasty [2, 4, 10]. However, the finding of an eccentric joint space showed just as strong an association with the change to Charnley Class $\mathrm{B}$ as the minimum joint space width in a preliminary bivariate analysis (HR, 12; $\mathrm{p}=0.001)$. We elected to use the minimum joint space width in our multivariate model to avoid collinearity, but a difference of $1 \mathrm{~mm}$ or more between minimum and maximum joint space should be considered a strong predictor of osteoarthritic development (Fig. 5). This eccentric joint space narrowing in all probability indicates a localized concentration of stress and becomes the key area for analysis in performing subsequent followup of the patients. Because our study focused on the development of $\mathrm{OA}$ in the contralateral hip in patients who already underwent hip arthroplasty, our results should be compared with caution with those of studies in which the development of OA was monitored on the first diseased hip. Patients who already have had one hip replaced may be more likely to have the second hip operated on earlier during the development process of OA than the first hip. In addition, during the same period the study subjects had their surgery performed, 312 patients who presented with primary $\mathrm{OA}$ and bilateral pain of various levels were treated with hip arthroplasty at our center. Ninety-five (30\%) had unilateral treatment and did not have sufficient pain develop to require contralateral surgery, $124(40 \%)$ had bilateral surgery in a two-stage procedure, and $93(30 \%)$ had bilateral surgery in a onestage procedure as the joint disease was sufficient on both sides to require short-term arthroplasties. We did not find any association between sex and the incidence of hip arthroplasty which would seem in contrast to the results of Hawker et al. [12] who found a greater level of underuse of arthroplasty (hip or knee) in women than in men. However, they also found that this difference may be attributable to the referral system and did not exist once the patients had consulted an orthopaedic surgeon. This is consistent with our results on the contralateral hip, as our patients were already closely followed by an orthopaedist.

Our separate analysis for patients with high and low center-edge angles showed a differentiation in the effect of a low head-to-neck ratio (strongly associated with pistolgrip deformity) on the outcome measurement (the time to 

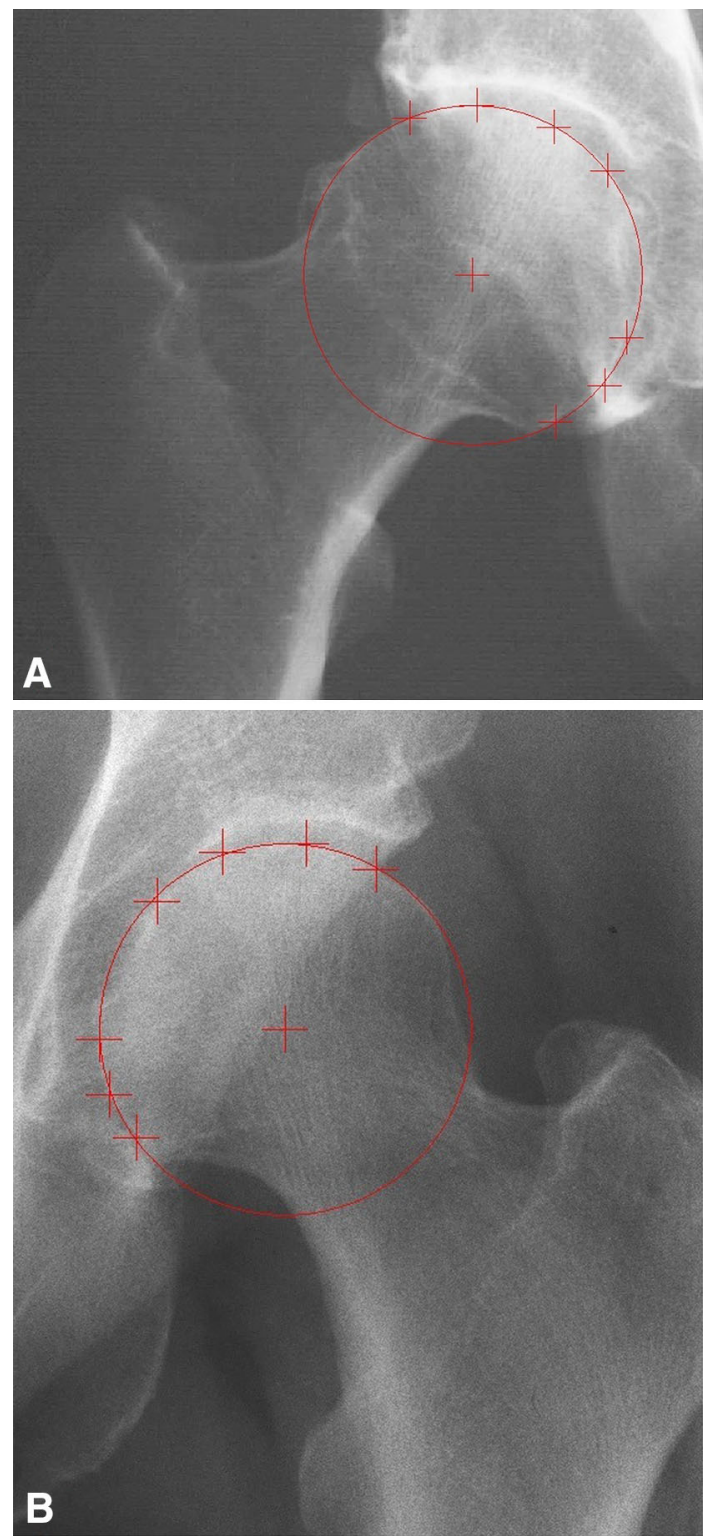

Fig. 5A-B (A) The baseline radiograph shows the hip of a 58-yearold man. The narrow part of the joint space is lateral to the widest part. The patient progressed to Charnley Class B disease after 25 months with rather rapid additional narrowing and obliteration of the joint space despite a low activity level. He underwent contralateral hip arthroplasty 4.5 years after the initial surgery. (B) The baseline radiograph of the hip a 59-year-old woman is shown. The narrow part of the joint space is medial to the widest part. The patient progressed to Charnley Class B disease after 4 years with additional joint space narrowing and despite reduced activity level underwent contralateral hip arthroplasty 7.5 years after the initial surgery.

progression to Charnley Class B disease). It is possible that a shallow acetabulum prevents impingement to a certain extent. This is, to our knowledge, the first time such an association has been made. This result is particularly important because it explains in part why patients with pistol-grip deformities do not always have symptomatic
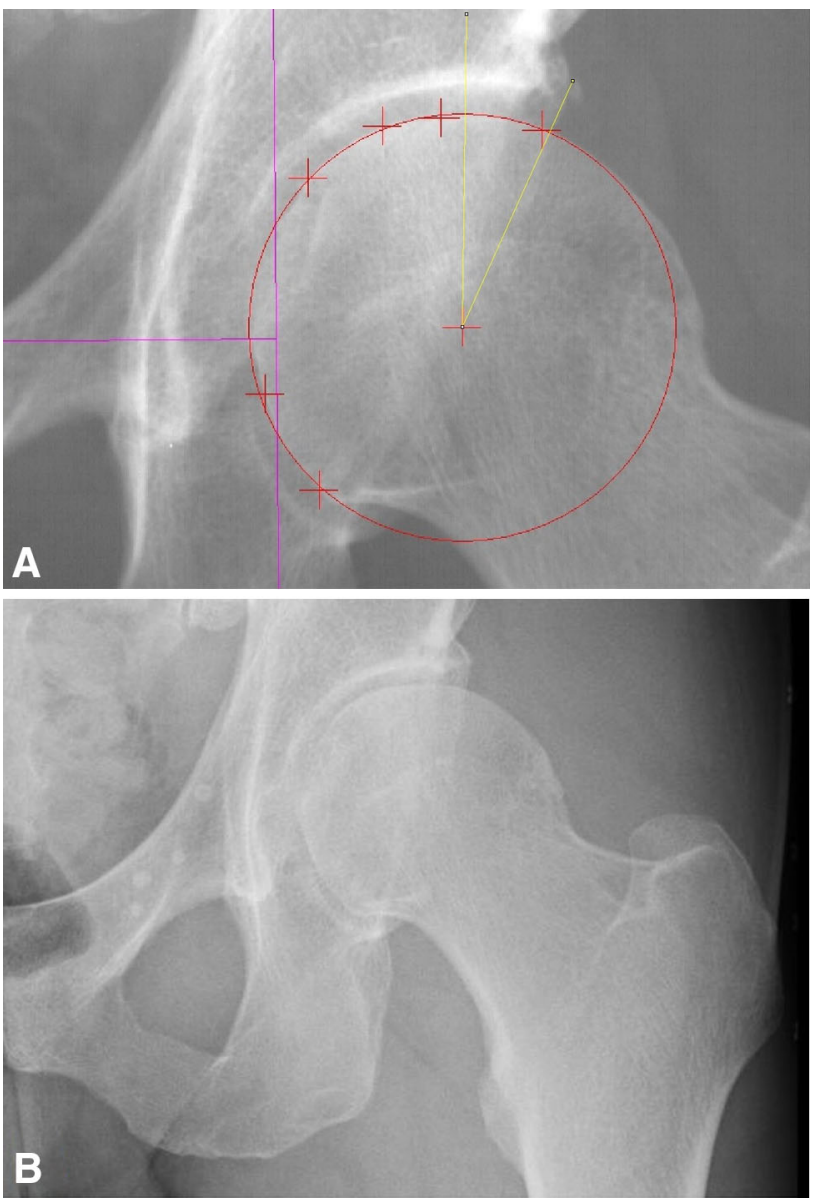

Fig. 6A-B (A) The baseline radiograph of the hip of a 44-year-old man is shown. The center-edge angle is $23^{\circ}$ and the head-to-neck ratio is 1.13. The joint space is quite concentric. There is suggestion of a small osteophyte beginning to form superiorly in the fovea. The subchondral sclerosis is fairly uniform superiorly. (B) A postoperative radiograph taken 13 years after the baseline shows the head and acetabulum are still concentric but the osteophyte from the roof of the fovea is more prominent and the subchondral sclerosis more circumferential. However, the joint space is still preserved although slightly narrower. The patient is still pain-free 15 years after the initial evaluation. At 60 years old, his UCLA activity score is 7 . He works out regularly, hikes, and does some martial arts.

OA develop with time (Fig. 6). Conversely, a head-to-neck ratio of 1.3 or less increased the chances of progressing to Charnley Class B disease (Table 3). One could wonder why these hips with low center-edge angles were included in the study because we selected patients who underwent hip arthroplasty for idiopathic OA. The patients were selected based on the diagnosis of the surgically treated hip, but the study was performed on the contralateral hip and we found that 62 of these patients had a center-edge angle of $25^{\circ}$ or less (which is one criterion for a diagnosis of developmental dysplasia of the hip) in the contralateral hip. These patients might have had borderline features of dysplasia on the surgically treated hip but not to the extent 
that a clear diagnosis of developmental dysplasia of the hip could be made, also considering that the first radiographs of these hips showed end-stage osteoarthritic degeneration.

We found that the incidence of OA developing in the contralateral hip in patients with unilateral OA is $41 \%$ at 10 years, with 19\% undergoing hip arthroplasty, and that reduced minimum joint space width, low center-edge angle, low head-to-neck ratio, and presence of osteophytes were associated with the development of contralateral OA. These variables can easily be assessed from an AP pelvis radiograph so physicians can predict the occurrence of contralateral OA and the need for future hip arthroplasty in patients who had a unilateral arthroplasty. However, the data available may have led us to underestimate the need for contralateral arthroplasty, as a substantial portion (22\%) had not been followed for the last 5 years and $8 \%$ were missing 2-year radiographic data. Future studies with a prospective design should aim at completing the list of radiographic features associated with the development of OA by adding a review of lateral radiographs.

\section{References}

1. Amstutz H, Thomas B, Jinnah R, Kim W, Grogan T, Yale C. Treatment of primary osteoarthritis of the hip: a comparison of total joint and surface replacement arthroplasty. J Bone Joint Surg Am. 1984;66:228-241.

2. Chu Miow Lin D, Reichmann W, Gossec L, Losina E, Conaghan $\mathrm{P}$, Maillefert J. Validity and responsiveness of radiographic joint space width metric measurement in hip osteoarthritis: a systematic review. Osteoarthritis Cartilage. 2011;19:543-549

3. Clohisy J, Dobson M, Robison J, Warth L, Zheng J, Liu S, Yehyawi T, Callaghan J. Radiographic structural abnormalities associated with premature, natural hip-joint failure. J Bone Joint Surg Am. 2011;93(suppl 2):3-9.

4. Conrozier T, Jousseaume C, Mathieu P, Tron A, Caton J, Bejui J, Vignon E. Quantitative measurement of joint space narrowing progression in hip osteoarthritis: a longitudinal retrospective study of patients treated by total hip arthroplasty. Br J Rheumatol. 1998;37:961-968.

5. Conrozier T, Lequesne M, Favret $\mathrm{H}$, Taccoen A, Mazières B, Dougados M, Vignon M, Vignon E. Measurement of the radiological hip joint space width: an evaluation of various methods of measurement. Osteoarthritis Cartilage. 2001;9:281-286.
6. DeLee J, Charnley J. Radiological demarcation of cemented sockets in total hip replacement. Clin Orthop Relat Res. 1976;121:20-32.

7. Dorey F, Amstutz HC. The validity of survivorship analysis in total joint arthroplasty [see comments]. J Bone Joint Surg Am. 1989;71:544-548.

8. Eijer H, Leunig M, Mahomed MN, Ganz R. Cross-table lateral radiographs for screening of anterior femoral head-neck offset in patients with femoro-acetabular impingement. Hip Int. 2001;11:37-41.

9. Ganz R, Parvizi J, Beck M, Leunig M, Notzli H, Siebenrock K. Femoroacetabular impingement: a cause for osteoarthritis of the hip. Clin Orthop Relat Res. 2003;417:112-120.

10. Goker B, Doughan A, Schnitzer T, Block J. Quantification of progressive joint space narrowing in osteoarthritis of the hip: longitudinal analysis of the contralateral hip after total hip arthroplasty. Arthritis Rheum. 2000;43:988-994.

11. Harris W. Etiology of osteoarthritis of the hip. Clin Orthop Relat Res. 1986;213:20-33.

12. Hawker G, Wright J, Coyte P, Williams J, Harvey B, Glazier R, Badley E. Differences between men and women in the rate of use of hip and knee arthroplasty. N Engl J Med. 2000;342:10161022.

13. Ipach I, Mittag F, Syha R, Kunze B, Wolf P, Kluba T. Indications for total hip arthroplasty in young adults: idiopathic osteoarthritis seems to be overestimated. Rofo. 2012;184:239-247.

14. Ipach I, Rondak I, Sachsenmaier S, Buck E, Syha R, Mittag F. Radiographic signs for detection of femoroacetabular impingement and hip dysplasia should be carefully used in patients with osteoarthritis of the hip. BMC Musculoskelet Disord. 2014;15:150.

15. Klit J, Gosvig K, Jacobsen S, Sonne-Holm S, Troelsen A. The prevalence of predisposing deformity in osteoarthritic hip joints. Hip Int. 2011;21:537-541.

16. Maillefert J, Sharp J, Aho L, Dougados M. Comparison of a computer based method and the classical manual method for radiographic joint space width assessment in hip osteoarthritis. $J$ Rheumatol. 2002;29:2592-2596.

17. Murray D, Britton A, Bulstrode C. Loss to follow-up matters. $J$ Bone Joint Surg Br. 1997;79:254-257.

18. Ritter M, Carr K, Herbst S, Eizember L, Keating E, Faris P, Meding J. Outcome of the contralateral hip following total hip arthroplasty for osteoarthritis. J Arthroplasty. 1996;11:242-246.

19. Şahin N, Atici T, Öztürk A, Özkaya G, Özkan Y, Avcu B. Prevalence of femoroacetabular impingement in asymptomatic contralateral hips in patients with unilateral idiopathic osteoarthritis. J Int Med Res. 2011;39:790-797.

20. Vossinakis I, Georgiades G, Kafidas D, Hartofilakidis G. Unilateral hip osteoarthritis: can we predict the outcome of the other hip? Skeletal Radiol. 2008;37:911-916.

21. Wiberg G, Shelf operation in congenital dysplasia of the acetabulum and in subluxation and dislocation of the hip. $J$ Bone Joint Surg Am. 1953;35:65-80. 